\title{
A Comparative Study of Construction Waste Generation Rate Based on Different Construction Methods on Construction Project in Malaysia
}

\author{
Haritharan Maniam \\ Faculty of Civil and Environmental \\ Engineering, Universiti Tun Hussein Onn \\ Malaysia (UTHM), Parit Raja, Malaysia
}

\author{
Sasitharan Nagapan \\ Faculty of Civil and Environmental \\ Engineering, Universiti Tun Hussein Onn \\ Malaysia (UTHM), Parit Raja, Malaysia \\ sasitharan@uthm.edu.my
}

\author{
Abd Halid Abdullah \\ Faculty of Civil and Environmental \\ Engineering, Universiti Tun Hussein Onn \\ Malaysia (UTHM), Parit Raja, Malaysia
}

Shivaraj Subramaniam

Faculty of Civil and Environmental Engineering, Universiti Tun Hussein Onn Malaysia (UTHM), Parit Raja, Malaysia

\author{
Samiullah Sohu \\ Faculty of Civil and Environmental Engineering, \\ Universiti Tun Hussein Onn Malaysia (UTHM), \\ Parit Raja, Malaysia
}

\begin{abstract}
High construction waste (CW) generation in Malaysia has serious impacts although there are very little available data regarding the relevant issue in Malaysia. This lack of data results in improper CW management and $\mathrm{CW}$ disposal without proper control measures. To control the implications of $\mathrm{CW}$, it is very important to understand their quantity which is currently unknown. Past researches in Malaysia, found that $\mathrm{CW}$ generation was affected by construction methods (CMs) practiced on site. The aim of this study is to compare the $\mathrm{CW}$ generation rate between different $\mathrm{CMs}$ for on-going construction projects in Malaysia. Common CMs practiced in Malaysia are conventional construction method (CCM), mixed construction method (MCM) and industrialized building system (IBS). To obtain CW generation data, site visit (SV) method, which consists of direct measurement (DM) and indirect measurement (IM) is applied to this study. CCM was recorded to have the highest amount of waste. IBS method records 77.188 tons and MCM 53.191 tons. Regarding the average waste generation rate (AWGR), IBS recorded a value of 0.018 tons per square meter, while MCM recorded 0.030 tons per square meter and $C C M$ recorded the highest amount of 0.046 tons per square meter.
\end{abstract}

Keywords-construction waste generation; construction method

\section{INTRODUCTION}

Construction sector has an important role in promoting economy growth in Malaysia [1]. Many infrastructure projects and buildings have been built [2] and $\mathrm{CW}$ in landfill results in a large burden and a costly issue for solid waste management [3]. Wastes have the potential to affect the human well-being and environment [4]. Despite the fact that this problem has caught the attention of the media for a long time, measures taken to control the waste generation are very few [5]. Attention towards $\mathrm{CW}$ was only given after the implications have increased regarding environmental issues [6]. There is no printed and reliable data related to $\mathrm{CW}$ in Malaysia [1, 7]. In addition, Malaysia still lacks researches on CW generation [8]. The general components in $\mathrm{CW}$ are inert materials (e.g. concrete, timber, metal, bricks, etc.), which cause small damage to the environment. Proper CW measurement is vital to initiate an effective management at both project and regional level [9]. CW generation is affected by a few factors in the construction field, like improper management, low awareness, rules and regulations. CW generation also depends on the $\mathrm{CM}$ practiced and materials utilized at construction sites [10]. The limited number of $\mathrm{CW}$ generation data attracts the attention of local researchers to explore this field.

\section{LITERATURE REVIEW}

\section{A. Types of $\mathrm{CMS}$}

According to researches from Table I, the CMs implemented in Malaysia are, conventional construction method (CCM), mixed construction method (MCM) and industrialized building system (IBS) method.

TABLE I. CONSTRUCTION METHODS USED IN MALAYSIA

\begin{tabular}{|c|c|c|c|}
\hline \multirow{2}{*}{ Reference } & \multicolumn{3}{|c|}{ Construction method } \\
\cline { 2 - 4 } & CCM & IBS & MCM \\
\hline$[1]$ & $\bullet$ & $\bullet$ & $\bullet$ \\
\hline$[8]$ & $\bullet$ & & $\bullet$ \\
\hline$[13]$ & $\bullet$ & $\bullet$ & \\
\hline
\end{tabular}

\section{B. CW Issues in Malaysia}

The construction industry plays a significant role in Malaysia's development both in infrastructure and economic sectors. Malaysian construction industry has experienced a vast development over the last 20 years. Almost all projects carried out are very complex, and require higher skills with superior technologies, fast track and concurrent practices of work and 
higher competitive terms of price [11]. In Malaysian construction industry, data availability is not satisfactory even for current projects [12]. Moreover, the construction industry's impact on nature is noteworthy as the major infrastructure projects high demands, residential and commercial constructions are generating high volumes of CW [13]. Countries like Malaysia tend to concentrate more in the topic of construction and demolition waste generation, including waste causes, waste generation rate, and factors affecting waste generation, because these portions have received higher attention.

\section{Construction Waste Density}

The construction waste calculated from this study will be either in $\mathrm{m}^{3}$ or metric tons. The waste composition density is used to convert the waste into tonnage. Table II shows the waste composition density obtained by Solid Waste and nonphysical waste obtained by Public Cleansing Management Corporation (SWCorp) [5]. Unit density is used to convert $\mathrm{m}^{3}$ to tons.

TABLE II. DENSITY OF WASTE COMPOSITION

\begin{tabular}{|c|c|}
\hline Waste Composition & Density, $\left.\mathbf{~ ( t o n} / \mathbf{m}^{\mathbf{3}}\right)$ \\
\hline Concrete & 1.27 \\
\hline Soil and Aggregates & 1.25 \\
\hline Brick & 1.20 \\
\hline Tiles and ceramics & 0.59 \\
\hline Metal & 0.42 \\
\hline Timber & 0.34 \\
\hline Glass & 0.61 \\
\hline Plastics & 0.23 \\
\hline Paper and cardboard & 0.21 \\
\hline Mixed Waste/ Demolition Waste & 1.40 \\
\hline
\end{tabular}

\section{Study Objectives}

This study aims to compare $\mathrm{CW}$ generation rates between different CMs for on-going construction projects in Malaysia. To achieve this aim, the objectives of this study are:

1. To identify current $\mathrm{CMs}$ practiced at construction sites.

2. To quantify $\mathrm{CW}$ generation rate for each $\mathrm{CM}$.

3. To compare the CM generation rate among different CMs.

\section{RESEARCH METHODOLOGY}

This methodology is implemented by visiting the construction site for a field survey defined in terms of field measurement (FM). This method consists of direct and indirect measurements to collect $\mathrm{CW}$ generation data.

\section{A. Direct Measurements}

This method measures on site the weight of the waste produced or its volume. Some assumptions must be made prior to direct measurement. Four assumptions were made depending on how CW was stockpiled, gathered, scattered or stacked. For stockpiled waste, a rectangular based pyramid was assumed, and the volume was calculated by:

$$
V S=\frac{1}{3} L \times B \times H
$$

For gathered waste, the layout shape was assumed cuboid, and the volume $(\mathrm{Vg})$ was derived from:

$$
V g=L \times B \times H
$$

\section{B. Indirect Measurements}

For indirect measurements, truck load records were used to estimate the CW volume generated on site. The containers' volume and the number of trucks for waste collecting were recorded.

\section{C. $C W$ Generation Rate Calculation}

The principle of this methodology is to obtain the waste generation rate in ton $/ \mathrm{m}^{2}$ (weight per construction area). Total area of the project floor needs to be calculated from the building plan and recorded for calculation of waste generation rate. The waste generation rate can be calculated from:

$$
C=W / G F A
$$

where $W$ is the total waste generated from construction project (tons), GFA is the gross floor area and $C$ is the waste generation rate in ton $/ \mathrm{m}^{2}$.

\section{RESULTS AND DISCUSSION}

Obtained results were sorted according to the three CMs stated previously, namely conventional construction method (CCM), industrialized building system (IBS), and mixed construction method (MCM). Each building site was monitored for 3 months in order to obtain the data. All chosen sites were at the construction stage.

\section{A. Total Construction Waste}

Waste data are shown in Table III.

TABLE III. TOTAL WASTE FOR EACH SITE AND CM

\begin{tabular}{|c|c|}
\hline Project/Site & Total Waste (Tons) \\
\hline CCM 1 & 276 \\
\hline CCM 2 & 241.334 \\
\hline CCM 3 & 192.414 \\
\hline CCM 4 & 80.878 \\
\hline IBS 1 & 98.89 \\
\hline IBS 2 & 49.83 \\
\hline IBS 3 & 112 \\
\hline IBS 4 & 48.03 \\
\hline MCM 1 & 10.824 \\
\hline MCM 2 & 28.36 \\
\hline MCM 3 & 25.02 \\
\hline MCM 4 & 148.56 \\
\hline
\end{tabular}

\section{B. Construction Waste Generation}

\section{1) Conventional Construction Method (CCM)}

Figure 1 illustrates, three months of construction waste data collected for CCM sites. These data were collected continuously by following the site progress. Total waste generated by every site was calculated. We see that CCM 1 records the highest amount of waste. The least amount of wastes is recorded in CCM 4.

\section{2) IBS Method}

Four sites were selected regarding IBS method. Data were collected separately for each site. The collected data are shown 
in Figure 2. The highest amount of total waste was produced from IBS 3. The second highest amount of waste was recorded from IBS 1. IBS 2 and 4 produced the same amount of total waste. The waste generation for each site is not the same every month. The least amount of waste production was during the first month of measurements on IBS 4.

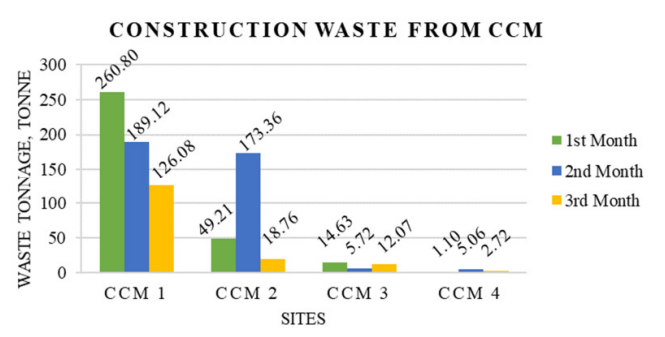

Fig. 1. Construction waste obtained from CCM sites

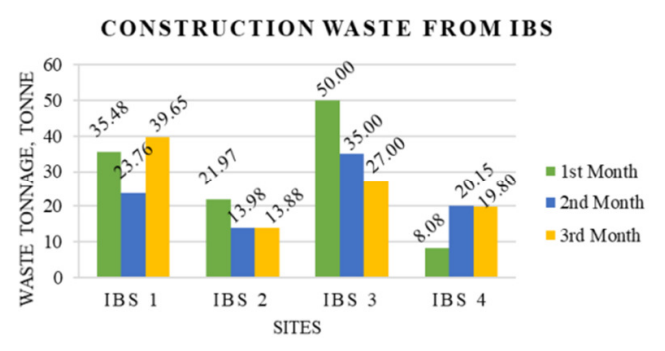

Fig. 2. Construction waste obtained from IBS sites

\section{3) $M C M$}

The next four sites were chosen for using MCM during construction. MCM involves combinations of CCM and IBS, therefore it is also known as partial IBS. In general terms, it is the introduction of IBS elements into conventional construction. Figure 3 shows the relative collected CW data.

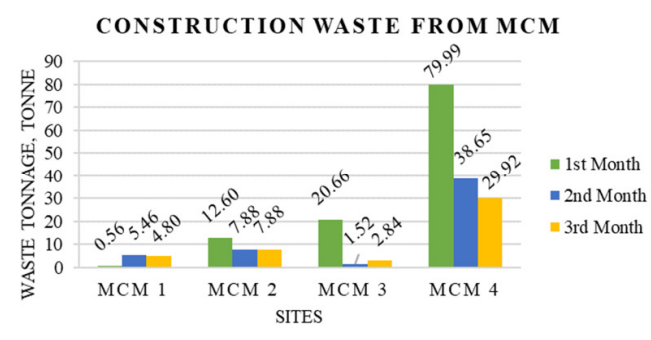

Fig. 3. Construction waste obtained from MCM site

The highest waste generation is from MCM 4. During the first month, MCM 4 recorded a huge amount of waste generation compared to the other four sites that used MCM. The second highest waste was produced from MCM 2. The third was MCM 3 and the least amount of waste was from MCM 1.

\section{Waste Generation Rate}

Waste data obtained for every site of the previous part are analyzed in this section. All data from the 12 sites are compared according to their construction methods. Following this, the gross floor area (GFA) of all sites is considered to draw the waste generation rate (WGR). WGR is used as a tool or a reference point at the construction industry to identify the waste generation rate per square meter. Thus, the more the GFA, the lesser the WGR should be.

\section{1) $C C M$}

The relative data are shown Table IV. The total average amount of waste generated for CCM sites is 197.657 tons. Table IV shows that, the highest WGR was produced by CCM 1 , which is 0.130 ton $/ \mathrm{m}^{2}$, and the second highest was from CCM 4 with 0.046 ton $/ \mathrm{m}^{2}$. The average WGR for the CCM sites is 0.046 ton $/ \mathrm{m}^{2}$.

TABLE IV. WASTE GENERATION RATE FOR CCM

\begin{tabular}{|c|c|c|c|}
\hline Project & Total CW (tons) & GFA ${\left(\mathbf{m}^{2}\right)}^{\mathbf{}}$ & WGR $\left(\right.$ ton $\left./ \mathbf{m}^{\mathbf{2}}\right)$ \\
\hline CCM 1 & 276 & 2121.17 & 0.130 \\
\hline CCM 2 & 241.334 & 187000 & 0.001 \\
\hline CCM 3 & 192.414 & 38853 & 0.005 \\
\hline CCM 4 & 80.878 & 1745 & 0.046 \\
\hline Average & 197.657 & - & 0.046 \\
\hline
\end{tabular}

2) $I B S$

Table V shows, the WGR for IBS method sites. IBS 1 had the the highest GFA, which was $58680 \mathrm{~m}^{2}$. The second highest GFA was from IBS 2, at $43200 \mathrm{~m}^{2}$. The average waste amount generated from this construction method was 77.188 tons. IBS 4 recorded the highest WGR, which was $0.012 \mathrm{ton} / \mathrm{m}^{2}$, followed by IBS 3, IBS 1 and IBS 2 whith $0.003,0.002$ and 0.001 ton $/ \mathrm{m}^{2}$ respectively. The average amount of WGR from IBS method sites is 0.018 ton $/ \mathrm{m}^{2}$.

TABLE V. WASTE GENERATION RATE FOR IBS

\begin{tabular}{|c|c|c|c|}
\hline Project & Total CW (tons) & GFA $\left(\mathbf{m}^{\mathbf{2}}\right)$ & WGR $($ ton \\
$\left.\mathbf{m}^{\mathbf{2}}\right)$ \\
\hline IBS 1 & 98.89 & 58680 & 0.002 \\
\hline IBS 2 & 49.83 & 43200 & 0.001 \\
\hline IBS 3 & 112 & 38410 & 0.003 \\
\hline IBS 4 & 48.03 & 4064 & 0.012 \\
\hline Average & 77.188 & - & 0.018 \\
\hline
\end{tabular}

\section{3) $M C M$}

The measure results are shown in Table VI. The highest GFA is from MCM 4, at $7460 \mathrm{~m}^{2}$ and the second biggest area is from MCM 1 at $1856 \mathrm{~m}^{2}$. The average waste amount for MCM sites is 53.191 tons. The highest WGR was from MCM 3 at 0.06 ton $/ \mathrm{m}^{2}$. Overall the average WGR for MCM sites is 0.03 ton $/ \mathrm{m}^{2}$.

TABLE VI. WASTE GENERATION RATE FOR MCM

\begin{tabular}{|c|c|c|c|}
\hline Project & Total CW (tons) & GFA $\left(\mathbf{m}^{\mathbf{2}}\right)$ & WGR $\left(\mathbf{t o n} / \mathbf{m}^{\mathbf{2}}\right)$ \\
\hline MCM 1 & 10.824 & 1856 & 0.006 \\
\hline MCM 2 & 28.36 & 1808 & 0.016 \\
\hline MCM 3 & 25.02 & 416 & 0.060 \\
\hline MCM 4 & 148.56 & 7460 & 0.020 \\
\hline Average & 53.191 & - & 0.030 \\
\hline
\end{tabular}




\section{Average Waste Generation Rate ( $A W G R$ )}

Figure 4 shows the average waste generated for each construction method.

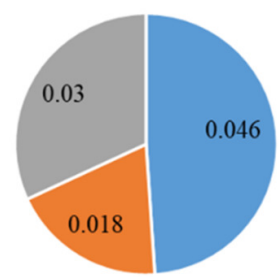

$=\mathrm{CCM}=\mathrm{IBS}=\mathrm{MCM}$

Fig. 4. AWGR for the different construction methods (ton $/ \mathrm{m}^{2}$ ).

When compared with the other two methods, CCM recorded the highest waste per area which is $0.046 \mathrm{ton} / \mathrm{m}^{2}$. The second highest was MCM with 0.03 ton $/ \mathrm{m}^{2}$. The least amount of waste generation per area was recorded for IBS sites, which was $0.018 \mathrm{ton} / \mathrm{m}^{2}$.

\section{CONCLUSION}

This paper introduced a study that relates construction method and construction waste generation rate. This study was conducted based on the construction methods existing in Malaysia. The aim and the three objectives of our research were achieved. The relationship between construction method and construction waste generation rate was revealed. From the research, we learned that the conventional method generates higher construction waste than the modern construction method or IBS. Construction waste generation study is wide and still at an early stage in Malaysia. Exploring on infrastructure project would be a pioneer for Malaysian construction waste generation studies. By conducting research on infrastructure projects, the importance of the study enhanced.

Furthermore, the relationship on the type of project and construction waste generation is a suggested future topic. This relationship will reveal whether the waste generation rate is affected by the type of project or not. Example of existing projects in Malaysia such as residential, non-residential, social amenities and infrastructure projects are recommended to be explored. Additionally, existing private and government projects in Malaysia should be considered in future studies. Recycle, reuse and reduce (3R) element will be an interesting part of future studies. By implementing $3 \mathrm{R}$ in construction waste, effective construction waste management practices would be identified. Indirectly, local contractors will be exposed to the sustainable development in the construction industry.

\section{REFERENCES}

[1] C. Mach, T. Fujiwara, C. S. Ho, "Construction and demolition waste generation rates for high-rise buildings in Malaysia", Waste Management \& Research, Vol. 34, No. 12, pp. 1224-1230, 2016

[2] V. W. Y. Tam, "Rate of Reusable and Recyclable Waste in Construction", The Open Waste Management Journal, Vol. 4, pp. 28-32, 2011

[3] P. J. Dolan, R. G. Lampo, J. C. Dearborn, Concepts for Reuse and Recycling of Construction and Demolition Waste, CERL Technical
Report 99/58, US Army Corps of Engineers, Construction Engineering Research Laboratories, 1999

[4] H. Arslan, N. Cosgun, B. Salg, "Construction and Demolition Waste Management in Turkey", in: Waste Management, An Intergraded Vision, InTechOpen, 2012

[5] S. Nagapan, I. A. Rahman, A. Asmi, N. F. Adnan, "Study of Site's Construction Waste in Batu Pahat, Johor", Procedia Engineering, Vol. 53, pp. 99-103, 2013

[6] T. U. Ganiron Jr, "Recycling Concrete Debris from Construction and Demolition Waste", International Journal of Advanced Science and Technology, Vol. 77, pp. 7-24, 2015

[7] S. Mahayuddin, J. Pereira, W. Badaruzzaman, M. Mokhtar, "Construction Waste Index for Waste Control in Residential House Project”, SB 10 New Zealand, Te Papa, New Zealand, May 26-28, 2010

[8] R. Noor, A. Ridzuan, I. Endut, B. Noordin, Z. Shehu, A. Ghani, "The quantification of local construction waste for the current construction waste management practices: A case study in Klang Valley", 2013 IEEE Business Engineering and Industrial Applications Colloquium, Langkawi, Malaysia, April 7-9, 2013

[9] H. Bergsdal, R. A. Bohne, H. Brattebo, "Projection of Construction and Demolition Waste in Norway", Journal of Industrial Ecology, Vol. 11, No. 3, pp. 27-39, 2008

[10] U. F. A. R. Mohammed, A. S. H. Mohamed, "A Glance on Construction Solid Waste Management in Khartoum", International Journal of Science, Engineering and Technology Research, Vol. 5, No. 1, pp. 101106,2016

[11] M. A. Eusuf, M. Ibrahim, R. Islam, "The Construction And Demolition Wastes In Klang Valley, Malaysia”, Planning Malaysia Journal, Vol. 10, No. 3, pp. 99-124, 2012

[12] R. A. Begum, C. Siwar, J. J. Pereira, A. H. Jaafar, "A benefit-cost analysis on the economic feasibility of construction waste minimisation: The case of Malaysia”, Resources, Conservation and Recycling, Vol. 48, No. 1, pp. 86-98, 2006

[13] S. K. Lachimpadi, J. J. Pereira, M. R. Taha, M. Mokhtar, "Construction waste minimisation comparing conventional and precast construction (Mixed System and IBS) methods in high-rise buildings: A Malaysia case study", Resources, Conservation and Recycling, Vol. 68, pp. 96103,2012 